\title{
Short cigarette smoke exposure facilitates sensitisation and asthma development in
} mice

\author{
Ellen A. Lanckacker*, Kurt G. Tournoy*, Hamida Hammad", Gabriele Holtappels`, \\ Bart N. Lambrecht ${ }^{\#}$, Guy F. Joos* and Tania Maes*
}

ABSTRACT: Epidemiological studies indicate that cigarette smoke exposure is a risk factor for increased sensitisation and asthma development. The aim of this study was to examine the impact of cigarette smoke on sensitisation and allergic airway inflammation in response to a low dose of house dust mite (HDM), and to obtain potential mechanistic insights.

Mice were exposed to low doses of HDM extract combined with air or cigarette smoke exposure, either during allergen sensitisation or during the development of allergic airway disease.

Mice concomitantly exposed to low-dose HDM, combined with cigarette smoke for 3 weeks, demonstrated an asthmatic phenotype with significantly increased airway eosinophilia, goblet cell metaplasia, airway hyperresponsiveness and a rise in HDM-specific serum immunoglobulin G1, compared to sole HDM or cigarette smoke exposure. In addition, short cigarette smoke inhalation, during the initial contact with HDM allergens, was sufficient to facilitate sensitisation and development of a complete asthmatic phenotype after rechallenge with HDM. Mechanistically, short cigarette smoke exposure amplified dendritic cell-mediated transport of fluorescein isothiocyanate-labelled HDM allergens to the intrathoracic lymph nodes and generated a local T-helper cell type 2 response.

Short cigarette smoke exposure is sufficient to facilitate allergic sensitisation and the development of low-dose HDM-induced allergic asthma, possibly by affecting dendritic cell function.

KEYWORDS: Airway allergy, dendritic cell, environmental pollutants, murine

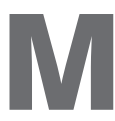
ost asthma begins in early childhood after sensitisation and re-exposure to ubiquitous environmental allergens, such as house dust mites (HDMs), moulds, plant pollen or animal dander. The risk for sensitisation is strongly dependent on the level of allergen exposure [1]. Over the last decades, the incidence of asthma has increased worldwide, especially in industrialised countries. This strong rise in asthma prevalence emphasises an important role for environmental and socio-economic conditions [2].

One of the main environmental risk factors associated with asthma is exposure to cigarette smoke [3]. Epidemiological studies have shown that smoking is responsible for higher asthma severity scores $[4,5]$, diminished lung function [5, 6] and poorer asthma control [7, 8]. Smoking is even associated with increased sensitisation to HDM allergens [9] and appears to be a risk factor for new-onset asthma among children and adults
[10-12]. The mechanisms mediating the adverse effects of smoking on asthma pathogenesis remain to be elucidated. Most murine models, designed to characterise the complex interaction between smoking and allergic airway inflammation, have relied on the sensitisation to the "surrogate" allergen ovalbumin (OVA) [13-18]. As OVA is an intrinsically inert protein, the role of cigarette smoke might have been overestimated in the past. Moreover, the differences in biochemical character between OVA and real-life allergens remain an undeniable limitation of the previously used OVA models.

To explain the observed increase in asthma prevalence due to cigarette smoke exposure, we hypothesised that cigarette smoke may lower the threshold for sensitisation to HDM allergens. We developed a clinically relevant murine model of allergic asthma, using low doses of HDM as a real-life aeroallergen, combined with cigarette
AFFILIATIONS

*Laboratory for Translational Research in Obstructive Pulmonary Diseases, Ghent University Hospital, Ghent,

\#Laboratory of Immunoregulation and Mucosal Immunology, Dept of Molecular Biomedical Research, VIB and Ghent University Hospital, Ghent, and

"Dept of Oto-Rhino-Laryngology, Ghent University, Ghent, Belgium.

CORRESPONDENCE

T. Maes

Ghent University Hospital

De Pintelaan 185

9000 Ghent

Belgium

E-mail: tania.maes@ugent.be

Received:

June 182012

Accepted after revision:

Aug 082012

First published online:

Aug 162012

European Respiratory Journal Print ISSN 0903-1936 Online ISSN 1399-3003 
smoke. We examined the effect of cigarette smoke on both sensitisation and ensuing asthma development and checked whether a few days of smoke exposure were sufficient to prime local sensitisation in the lymph nodes. Finally, we looked for potential mechanistic insights.

\section{METHODS}

\section{Mice}

Male BALB/c mice (6-8 weeks old) were purchased from Harlan (Zeist, the Netherlands). All in vivo manipulations were approved by the Animal Ethical Committee of the Faculty of Medicine and Health Sciences of Ghent University (Ghent, Belgium).

\section{Cigarette smoke exposure and HDM administration}

Mice ( $n=10$ per group) were subjected to whole-body cigarette smoke (3R4F Kentucky reference cigarettes; University of Kentucky, Lexington, KY, USA) as described previously [19]. Control mice were exposed to air. $30 \mathrm{~min}$ after the last smoke exposure, $25 \mu \mathrm{g}$ HDM extract (Dermatophagoides pteronyssinus; Greer Laboratories, Lenoir, NC, USA) (Der p $125.27 \mu \mathrm{g} \cdot \mathrm{mg}^{-1}$ protein; endotoxin $8.43 \mathrm{U} \cdot \mathrm{mg}^{-1}$ ) or PBS was administered intranasally in isoflurane-anaesthetised mice on days 0, 7 and 14 and mice were analysed on day 17 . To evaluate the impact of cigarette smoke on the development of HDM-induced allergic asthma, we performed protocol 1 (fig. 1). To unravel the impact of cigarette smoke during the sensitisation phase, mice were subjected to HDM and cigarette smoke according to protocol 2 or 4 (fig. 1). The impact of cigarette smoke during the challenge phase was evaluated using protocol 3 (fig. 1).

\section{Bronchoalveolar lavage and cytospins}

$24 \mathrm{~h}$ after the last smoke exposure and $72 \mathrm{~h}$ after the last HDM application, mice were euthanised with an overdose of pentobarbital (Sanofi-Ceva, Paris, France). Bronchoalveolar lavage (BAL), cytospins and cell differentiation were performed as described previously [19]. Remaining cells were used for fluorescence-activated cell sorter analysis.

Lung and mediastinal lymph node single-cell suspensions Lungs were perfused with saline plus EDTA through the pulmonary artery to remove contaminating blood cells. Lungs and mediastinal lymph nodes (mLNs) were removed and digested as described previously [20].

\section{Flow cytometry}

Staining procedures, data acquisition and analysis were performed as described previously [19]. Monoclonal antibodies (mAbs) used to identify mouse dendritic cell (DC) populations were anti-CD11c (clone HL3), anti-major histocompatibility complex (anti-MHC) class II (I-A/I-E, clone M5/114.15.2) and anti-CD11b (clone M1/70). CD11b ${ }^{+}$DCs were defined as CD11c-bright, low autofluorescent cells which strongly express MHC class II and CD11b on their surface. The following mAbs were used to stain mouse T-cell sub-populations: anti-CD3 (clone 145-2C11), anti-CD4 (clone GK1.5), anti-CD8 (clone 53-6.7) and anti-CD69 (clone H1.2F3) (all mAbs from BD Pharmingen, San Diego, CA, USA).

\section{mLN cell culture}

Paratracheal and parathymic intrathoracic lymph nodes were collected into sterile tubes containing cold $\left(4^{\circ} \mathrm{C}\right)$ tissue culture medium (TCM) and digested (as described above) to obtain a single cell suspension. TCM was prepared using RPMI 1640 supplemented with $10 \%$ fetal bovine serum, L-glutamine, penicillin/streptomycin and $\beta$-mercaptoethanol (all from Gibco BRL; Invitrogen Corp; Merelbeke, Belgium). Cells were then transferred in triplicate to round-bottomed, 96-well plates (Becton Dickinson, San Jose, CA, USA) with or without HDM extract $15 \mu \mathrm{g} \cdot \mathrm{mL}^{-1}$ culture medium, at a density of $2 \times 10^{5}$ cells per well, and incubated in a humidified $37^{\circ} \mathrm{C}$ incubator with $5 \% \mathrm{CO}_{2}$. After 5 days, supernatants were harvested and frozen for cytokine measurements.

\section{Histology}

The left lung was fixed in $4 \%$ paraformaldehyde and embedded in paraffin. Transversal sections of $3 \mu \mathrm{m}$ were stained with Congo Red (Klinipath, Olen, Belgium) to highlight eosinophils, with periodic acid-Schiff to identify goblet cells, or immunostained for $\alpha$-smooth muscle actin to evaluate airway smooth muscle content. Quantitative measurements

\section{Protocol 1}

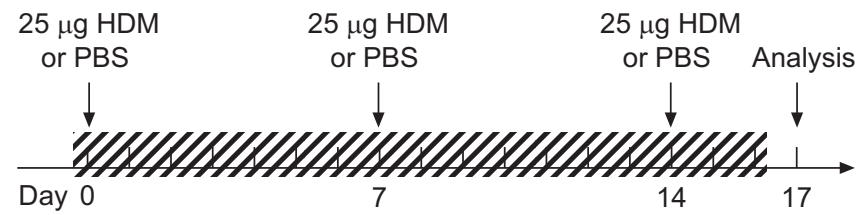

Protocol 2

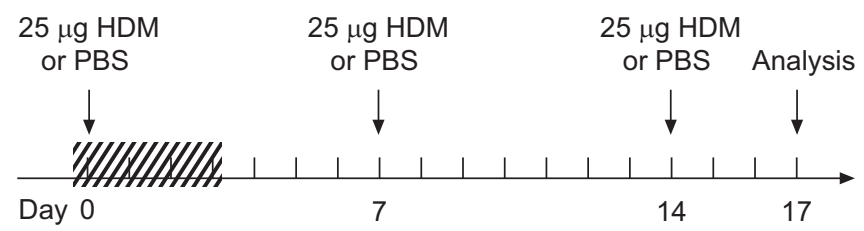

Protocol 3

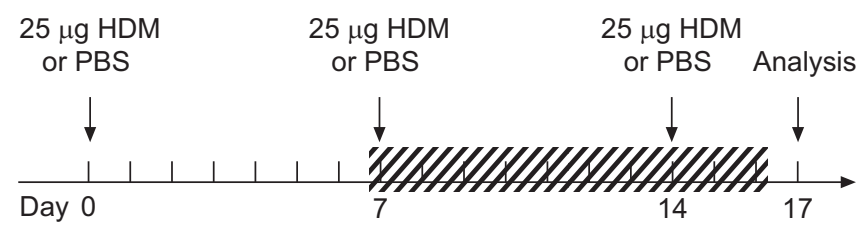

Protocol 4

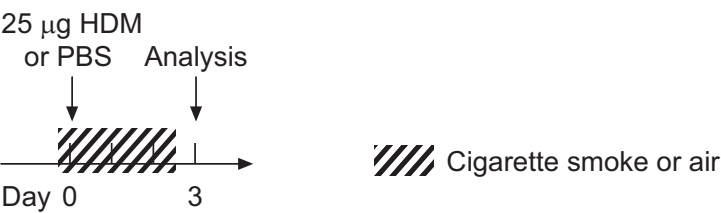

FIGURE 1. Exposure protocols. Four groups were included in our experimental set-up: PBS/air, PBS/cigarette smoke (sole cigarette smoke), house dust mite (HDM)/air (sole HDM) and HDM/cigarette smoke. Control mice were exposed to air. 
were performed using a Zeiss KS400 Image Analyzer platform (Oberkochen, Germany) as described previously [21]. To identify mast cells, lungs were stained with toluidin blue. The number of mast cells was counted per field (whole left lung lobe). Only those located in the airway wall were included for analysis.

\section{Protein measurements}

Total immunoglobulin (Ig)E was measured using coated microtitre plates and biotinylated polyclonal rabbit anti-mouse IgE (S. Florquin, Université libre de Bruxelles, Brussels, Belgium). For the detection of HDM-specific IgG1, microtitre plates were coated with HDM extract. Serum was added, followed by a horseradish peroxidase-conjugated polyclonal goat anti-mouse IgG1 antibody (Bethyl Laboratories, Montgomery, TX, USA). Levels of HDM-specific IgG1 were reported in optical densities. mLN supernatants were assayed for interleukin (IL)-4, IL-5, IL13 , IL-10 and interferon (IFN)- $\gamma$ by means of multiplex (Merck Millipore, Brussels, Belgium). In the supernatants of crushed lungs, IL-25, IL-33, thymic stromal lymphopoietin (TSLP), granulocyte-macrophage colony stimulating factor (GM-CSF) and IL-1 $\beta$ were measured using ELISA (R\&D Systems, Abingdon, UK) following the manufacturer's instructions.

\section{Assessment of airway responsiveness}

Airway responsiveness was measured in tracheostomised anaesthetised mice using the FlexiVent System (Scireq, Montreal, Canada). Neuromuscular blockade was induced by injecting pancuronium bromide $\left(1 \mathrm{mg} \cdot \mathrm{kg}^{-1}\right)$ intravenously. To check for airway hyperresponsiveness, mice were challenged with increasing doses of carbachol $(0,5,10,20,40,80,160$ and $\left.320 \mu \mathrm{g} \cdot \mathrm{kg}^{-1}\right)$. A "snapshot perturbation" manoeuvre was imposed to measure the (dynamic) resistance of the whole respiratory system (airways, lung and chest wall). For each mouse, a dose-response curve was generated and the area under the curve was calculated.

\section{Evaluation of DC migration by intratracheal instillation of fluorescent HDM}

To obtain fluorescently labelled HDM, HDM extract was dialysed against a carbonate-bicarbonate buffer ( $\mathrm{pH}$ 9.5) overnight at $4^{\circ} \mathrm{C} .10 \mathrm{mg} \cdot \mathrm{mL}^{-1}$ fluorescein isothiocyanate (FITC) in dimethyl sulfoxide (DMSO; Sigma Aldrich, Bornem, Belgium) was added to the HDM solution and rotated for $1 \mathrm{~h}$ at room temperature. The whole procedure was performed under dark, sterile conditions. After 4 days of cigarette smoke exposure, anaesthetised mice (i.p. ketamine (80 $\mathrm{mg} \cdot \mathrm{kg}^{1}$; Ketamine 1000 CEVA; Ceva Santé Animale, Brussels, Belgium) and xylazine $\left(8 \mathrm{mg} \cdot \mathrm{kg}^{-1}\right.$; Rompun $2 \%$; Bayer AG, Leverkusen, Germany)) were held vertically and $50 \mu \mathrm{L}$ of FITC-conjugated HDM $(100 \mu \mathrm{g})$ or PBS was pipetted just above their vocal cords. Mice were sacrificed 0, 24 and $48 \mathrm{~h}$ after instillation. The mLNs were removed and processed as described above. Discrimination in the $\mathrm{mLN}$ between the airway derived (AW) (CD11 $\left.\mathrm{c}^{\text {int-high }} / \mathrm{MHC} \mathrm{II}^{\text {high }}\right)$ and non-airway derived (NAW) DCs (CD11c ${ }^{+} / \mathrm{MHC} \mathrm{II}^{\text {int }}$ ) was performed using the method published by VERMAELEN et al. [20]. The percentage of HDM-bearing AW-DCs was determined by flow cytometry as the fraction of FITC $^{+} \mathrm{MHC}$ II $^{\text {high }}$ CD11 $c^{\text {int-high }}$ cells. The results were expressed as the percentage of $\mathrm{FITC}^{+}$DCs relative to the total DC population.

\section{Statistical analysis}

Statistical analysis was performed with PASW Statistics 18 (Chicago, IL, USA) using nonparametric tests. The different experimental groups were compared using a Kruskall-Wallis test for multiple comparisons. Pairwise comparisons were made using a Mann-Whitney U-test. A p-value $\leqslant 0.05$ was considered significant. Reported values are expressed as mean \pm SEM.

\section{RESULTS}

\section{Cigarette smoke facilitates the development of new-onset allergic asthma}

To evaluate the role of cigarette smoke in the pathogenesis of HDM-induced allergic asthma, BALB/c mice were exposed to cigarette smoke or air for 3 weeks and instilled with HDM $(25 \mu \mathrm{g})$ or PBS once a week (fig. 1, protocol 1). Compared with our previously described model [22], we instilled four-times less HDM in order to limit the biological effects of HDM on its own.
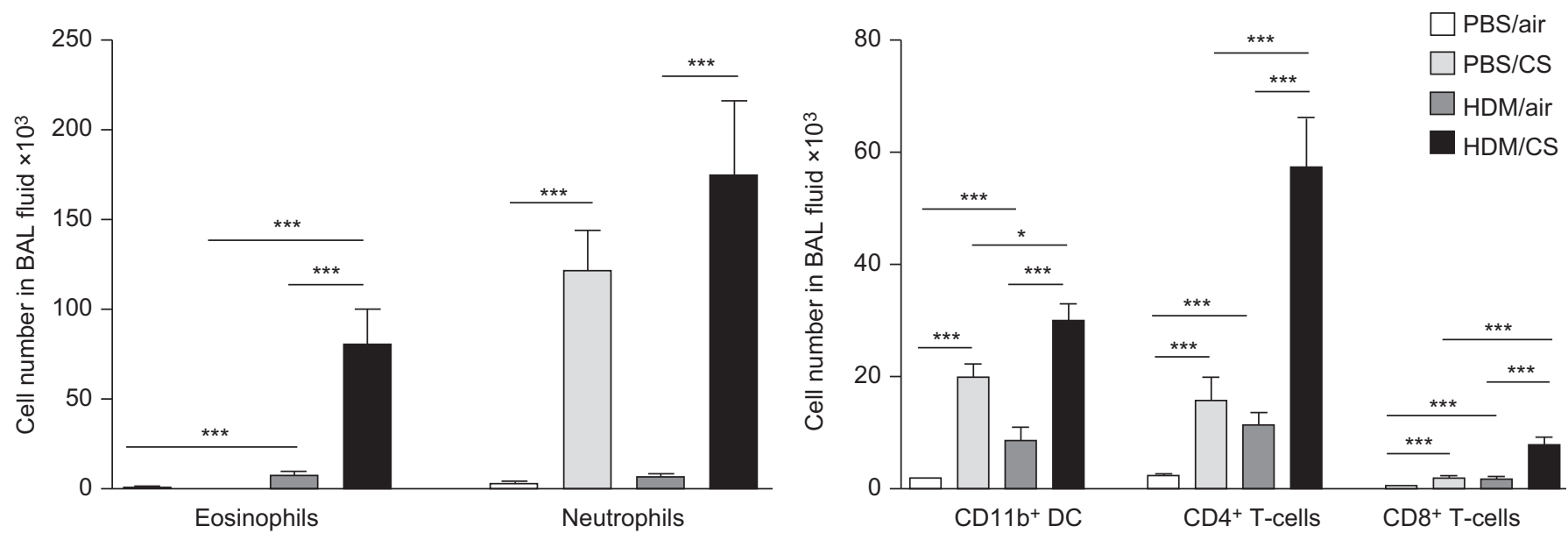

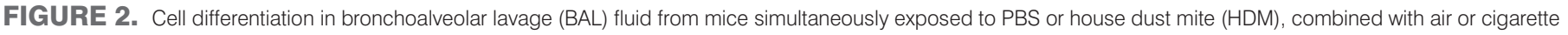
smoke (CS) for 3 weeks. Data are presented as mean \pm SEM; $n=10$ animals per group. DC: dentritic cells. *: $p<0.05 ;{ }^{\star} * \star: p<0.001$. 

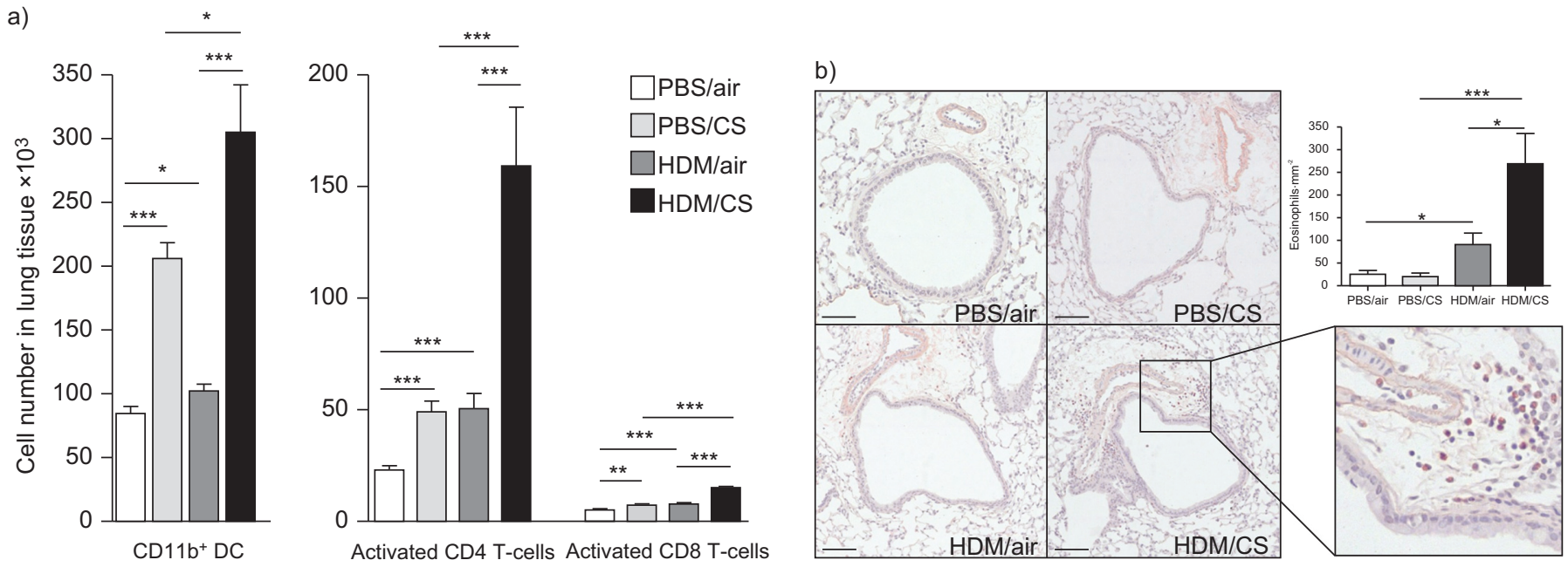

c)

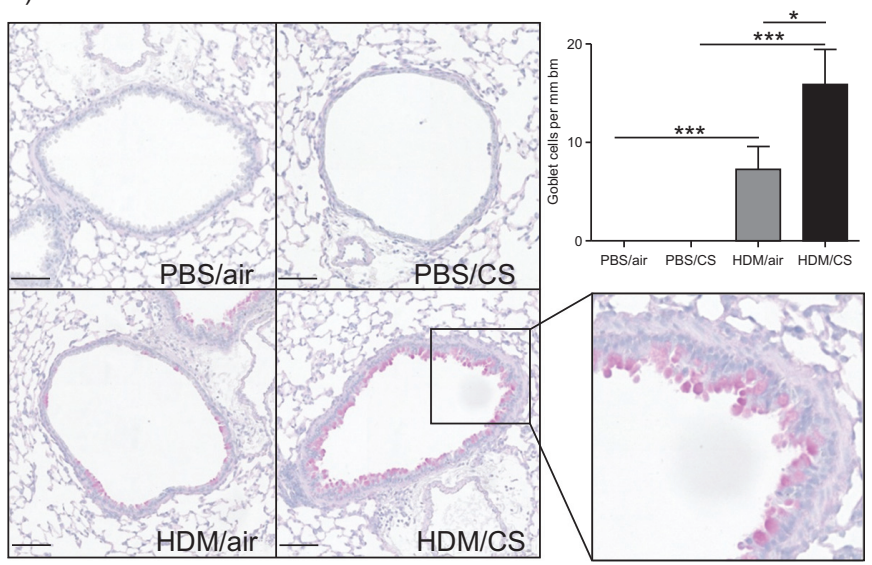

d)

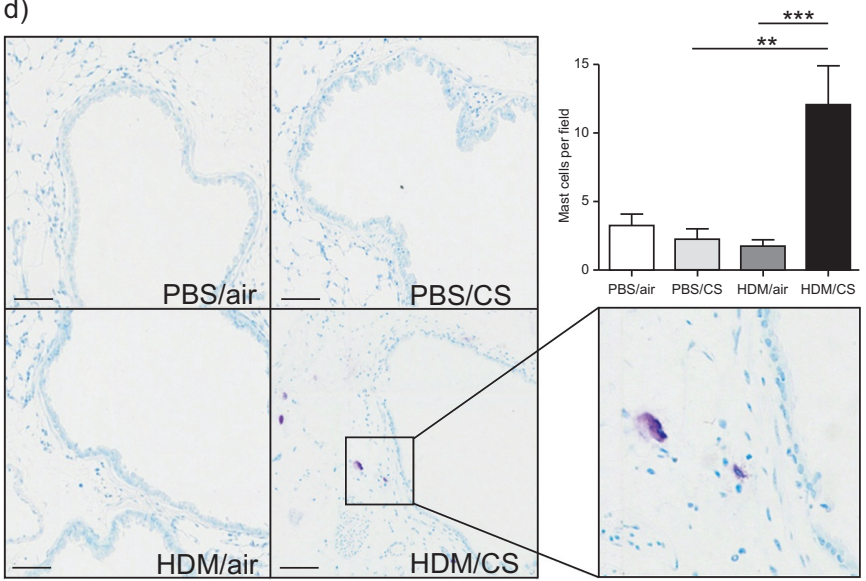

FIGURE 3. Cell differentiation in lung tissue and histopathological evaluation from mice simultaneously exposed to PBS or house dust mite (HDM), combined with air or cigarette smoke (CS) for 3 weeks. a) cell differentiation; photomicrographs of b) eosinophilic peribronchial infiltrates; c) goblet cells; and d) mast cells. Detail is shown in the enlarged boxes and quantification of cell numbers are shown in the graphs. Data are presented as mean \pm SEM; $n=10$ animals per group. DC: dendritic cells; bm: basement membrane.*: $p<0.05 ; * *: p<0.01 ; * *: p<0.001$

\section{Exposure to both HDM and cigarette smoke aggravates the} allergic response in BAL fluid and lung tissue

The intranasal delivery of sole HDM elicited a faint asthmatic phenotype with increased eosinophils, CD11b ${ }^{+}$DCs and CD4 $4^{+}$ and $\mathrm{CD}^{+} \mathrm{T}$ lymphocytes compared to PBS-exposed control mice (fig. 2). Cigarette smoke exposure enhanced the amount of total cells and macrophages (data not shown), neutrophils, CD11b DCs and $\mathrm{CD}^{+}$and $\mathrm{CD}^{+} \mathrm{T}$ lymphocytes in the BAL fluid compared to air-exposed mice (fig. 2). The concomitant exposure to HDM and cigarette smoke amplified the allergic phenotype considerably. This is reflected by a 10-fold increase in the number of eosinophils and a rise in $\mathrm{CD} 11 \mathrm{~b}^{+} \mathrm{DC}$ and $\mathrm{CD} 4^{+}$and $\mathrm{CD} 8^{+} \mathrm{T}$ lymphocytes in BAL fluid compared with the other groups. No further increases in macrophages (data not shown) or neutrophils were observed (fig. 2). Similarly, lung single-cell suspensions had more $\mathrm{CD} 11 \mathrm{~b}^{+} \mathrm{DCs}$ and activated $\mathrm{CD} 4^{+} \mathrm{CD} 69^{+}$and $\mathrm{CD} 8^{+} \mathrm{CD} 69^{+} \mathrm{T}-$ cells compared with sole HDM or cigarette smoke (fig. 3a). Histological analysis revealed peribronchovascular eosinophilic inflammation and mucin-producing goblet cells in HDMexposed mice, compared with naïve control mice (fig. $3 \mathrm{~b}$ and c). However, exposure to both cigarette smoke and HDM resulted in a further increase of eosinophils, goblet cells and mast cells (fig. 3b, c and d). Other features of airway wall remodelling, such as quantification of airway smooth muscle content, revealed no differences between the four groups (data not shown).

\section{Combined exposure to HDM and cigarette smoke increases HDM-specific lgG1 production in serum}

Total serum IgE did not differ between the four groups (data not shown), but HDM-exposed mice showed significantly elevated allergen-specific IgG1 titres in the serum, compared with naïve control mice. This level was further increased after combined exposure to HDM and cigarette smoke (fig. 4a). HDM-specific IgE measurements were below detection limits.

Concomitant exposure to HDM and cigarette smoke amplifies the production of T-helper cell type 2 cytokines

HDM restimulated mLN cells from the sole HDM group showed increased production of the inflammatory cytokines IL-4, IL-5, IL13 and IL-10, together with decreased levels of the typical Thelper cell (Th) type 1 cytokine IFN- $\gamma$ (fig. 4b). The HDM/ cigarette smoke combination yielded in a further increase in IL-4, 

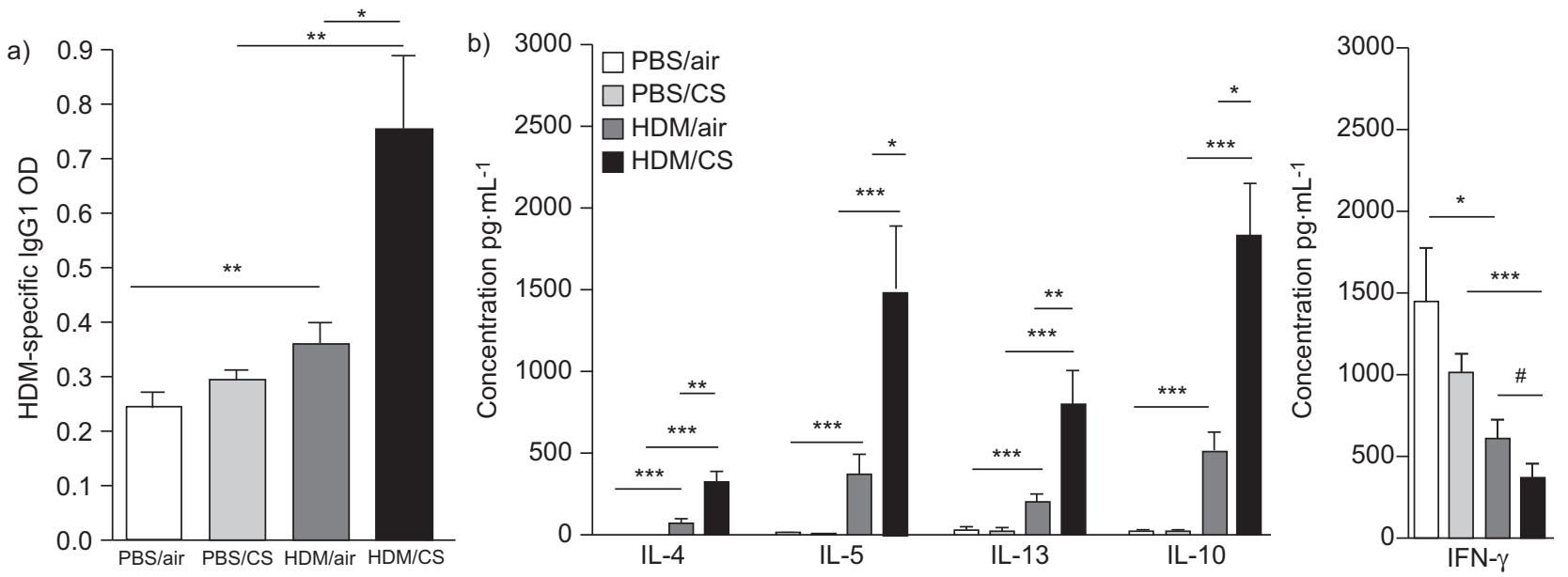

c)

d)
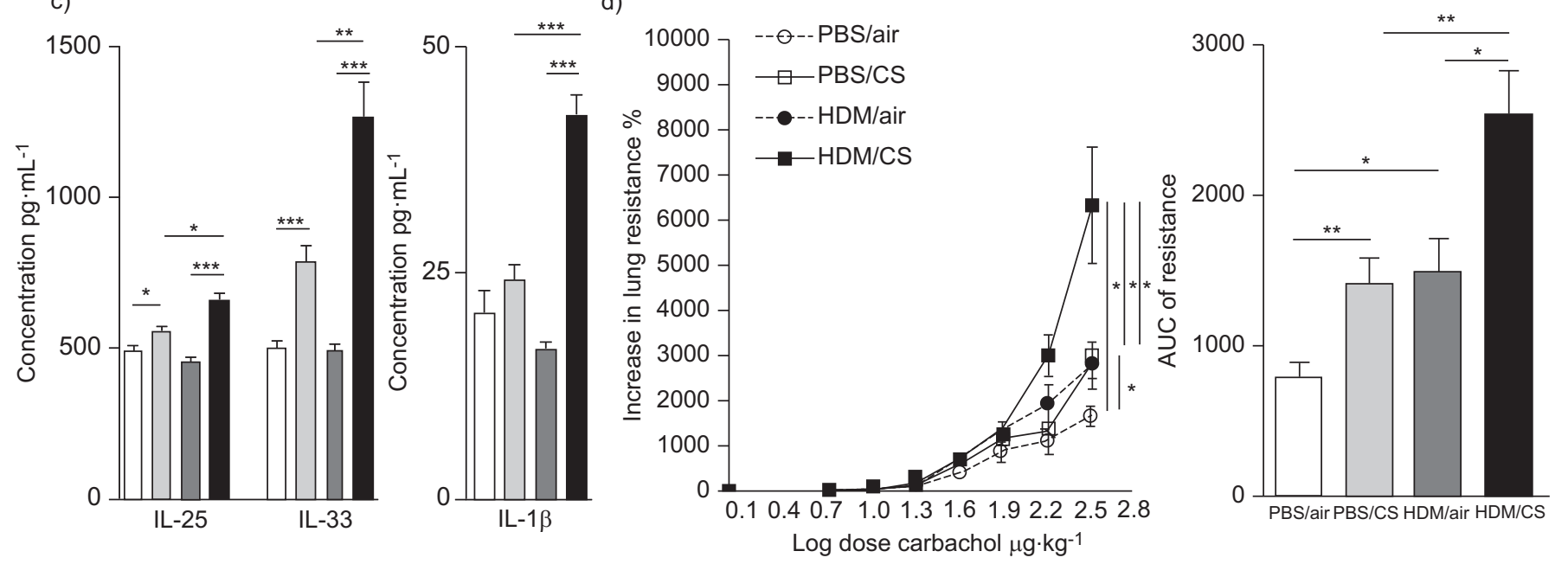

FIGURE 4. Immunoglobulins (Ig), cytokines and airway hyperresponsiveness of mice simultaneously exposed to PBS or house dust mite (HDM) combined with air or cigarette smoke (CS) for 3 weeks. a) HDM-specific IgG1; b) protein levels of interleukin (IL)-4, IL-5, IL-13, IL-10 and interferon (IFN)- $\gamma$ in the supernatant of HDM-restimulated lymph node cells; c) measurements of IL-25, IL-33 and IL-1 $\beta$ in supernatant of crushed lungs; and d) airway hyperresponsiveness to carbachol dose-response curve and area under the curve (AUC). Data are presented as mean \pm SEM; $n=10$ animals per group. OD: optical density; ${ }^{*}: p<0.05 ;{ }^{* *}: p<0.01 ;{ }^{* \star *}: p<0.001 ;{ }^{\#}: p=0.072$.

IL-5, IL-13 and IL-10 (fig. 4b). IFN- $\gamma$ had a further tendency to decrease (fig. $4 \mathrm{~b}$ ). The role of the epithelium was investigated by measuring innate pro-Th2 cytokines in lung homogenate. Exposure to both HDM and cigarette smoke resulted in more IL-25, IL-33 and IL-1 $\beta$ (fig. 4c). TSLP and GM-CSF were below detection limits.

\section{Cigarette smoke exposure exacerbates HDM-induced airway hyper responsiveness}

Figure $4 \mathrm{~d}$ shows the dose-response curve of the in vivo reactivity of all four groups. HDM- or cigarette smoke-exposed mice were slightly responsive towards the highest carbachol dose. Mice concomitantly exposed to both stimuli were more responsive (fig. $4 \mathrm{~d}$ ).

\section{Cigarette smoke exposure during sensitisation and not during allergen challenge is important for subsequent asthma development}

To investigate the putative role of cigarette smoke during sensitisation, BALB/c mice were briefly exposed to cigarette smoke (for 4 consecutive days) and instilled with HDM (25 $\mu \mathrm{g})$ once a week during 3 consecutive weeks (fig. 1, protocol 2). In the sera of HDM/cigarette smoke-exposed mice, enhanced allergen-specific IgG1 titres were detected (fig. 5a). In contrast to protocol 1, where mice received cigarette smoke for 3 weeks, we observed no neutrophils after limited cigarette smoke exposure in protocol 2 (fig. 5b). Mice concomitantly exposed to HDM and only 4 days of cigarette smoke showed more BAL $\mathrm{CD}_{11 b^{+}} \mathrm{DCs}, \mathrm{CD}^{+}$and $\mathrm{CD} 8^{+} \mathrm{T}$-lymphocytes in comparison to all other groups and had a 20-fold increase in the number of BAL eosinophils (fig. 5b). Compared to protocol 1, the inflammation in BAL fluid was less pronounced and, even in lung single cell suspensions, the number of DCs and Tlymphocytes no longer increased upon combined HDM/ cigarette smoke exposure (fig. 5c). However, histological examination revealed significantly more eosinophils (fig. $5 \mathrm{~d}$ ) and goblet cells in the airway wall (fig. 5e), together with increased airway hyperresponsiveness in concomitantly exposed mice (fig. 6a). Altogether, these Th2-associated airway responses were accompanied by increases in IL-4, IL-5, IL-13 

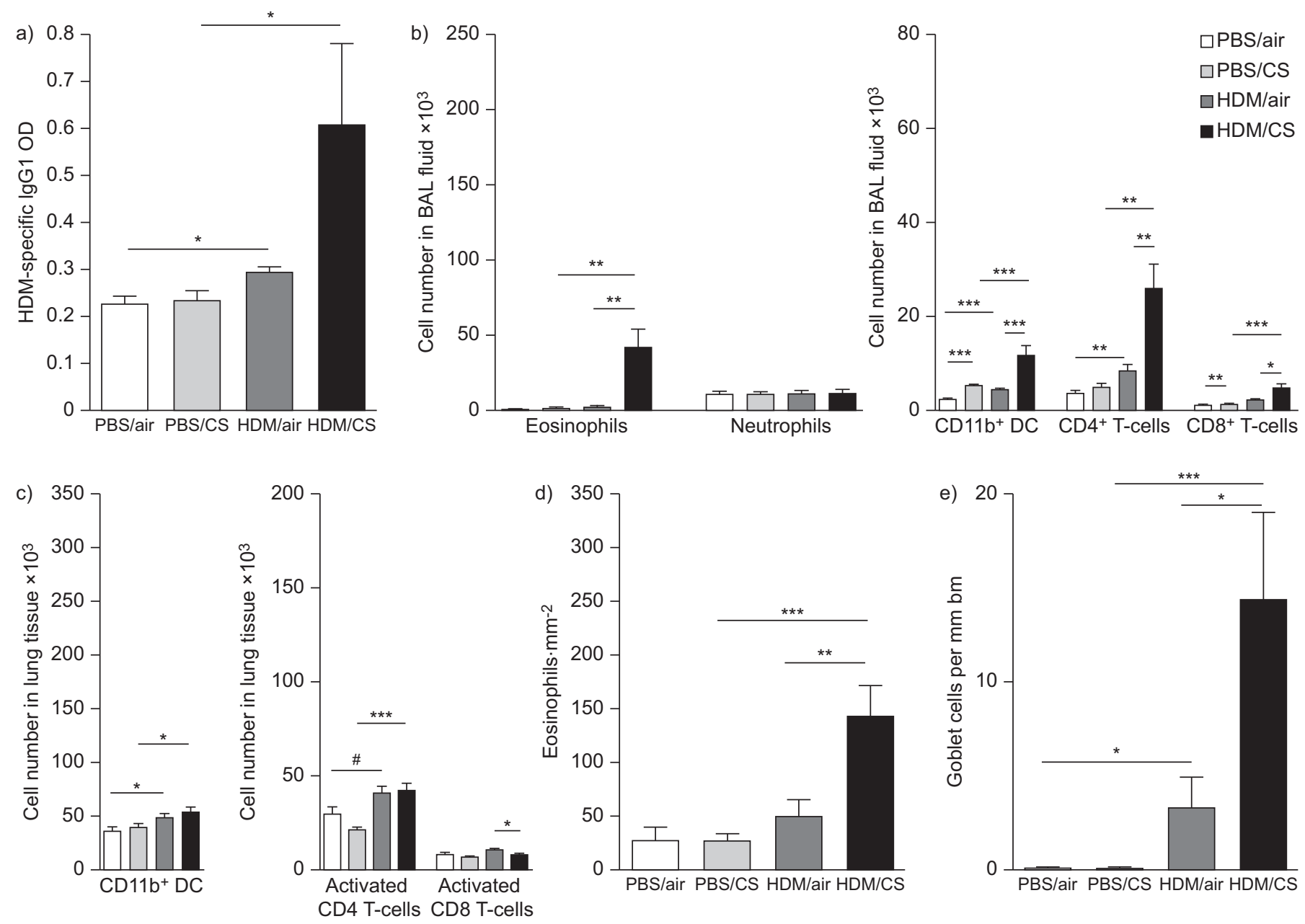

FIGURE 5. Immunoglobulins (Ig), inflammatory response and histopathological evaluation of mice simultaneously exposed to PBS or house dust mite (HDM) and 4 days of air or cigarette smoke (CS). a) HDM-specific IgG1; b) cell differentiation of bronchoalveolar lavage (BAL) fluid; c) lung digest; d) quantification of eosinophils; and e) measurement of goblet cells. Data are presented as mean \pm SEM; $n=10$ animals per group. OD: optical density; DC: dendritic cell; bm: basement membrance. *: $p<0.05$; $* *: p<0.01 ; * * *: p<0.001 ; *$ : $p=0.059$

and IL-10 in the supernatant of restimulated mLN cultures of HDM/cigarette smoke-exposed mice (fig. 6b), but no differences in IL-25, IL-33 and IL-1 $\beta$ production could be observed between all four groups (fig. 6c).

On the contrary, exposure to cigarette smoke exclusively during the HDM-challenge phase (fig. 1, protocol 3) was not able to induce an allergic phenotype and did not show increased HDM-specific IgG1 (fig. 7a), or elevated numbers of eosinophils, CD $11 b^{+}$DCs or T lymphocytes in BAL fluid (fig. 7b) and lung tissue, except for a rise of $\mathrm{CD} 4^{+} \mathrm{CD} 69^{+} \mathrm{T}$-cells in the lung (fig. 7c). Additionally, we found no increase in the number of goblet cells (fig. 7d) or airway hyperresponsiveness in these mice (fig. 7e).

\section{Short exposure to cigarette smoke enhances HDM uptake and $D C$ migration to the $m L N$ and facilitates sensitisation to common aeroallergens}

To investigate whether 4 days of smoke inhalation already affects airway DC trafficking and antigen transport to the draining LNs, we delivered fluorescently labelled HDM intratracheally to cigarette smoke- or air-exposed mice. FITC ${ }^{+}$DCs were exclusively found within the population of CD11 $c^{\text {int-high }}$ / MHC II ${ }^{\text {high }}$ AW-DCs. At various time-points after HDM instillation ( $24 \mathrm{~h}$ and $48 \mathrm{~h}$ ), cigarette smoke-exposed mice showed a marked increase in DC-mediated HDM transport to the draining LNs, compared with air-exposed mice (fig. 8a).

To characterise the role of cigarette smoke during initial sensitisation towards common aeroallergens, we exposed BALB/c mice to cigarette smoke for three consecutive days and instilled HDM allergens on the first day (25 $\mu \mathrm{g})$ (fig. 1, protocol 4). This short interaction between cigarette smoke and HDM allergens significantly increased the number of CD11b DCs in BAL fluid and lung tissue (fig. $8 \mathrm{~b}$ and c), with enhanced activation of BAL DCs, as demonstrated by the expression of CD86 (fig. 8b). At the functional level, we found that brief exposure to cigarette smoke during the first contact with HDM allergens was sufficient to induce sensitisation in the $\mathrm{mLN}$, characterised by a pronounced Th2 cytokine profile in HDM/ cigarette smoke-exposed mice (fig. 8d). To explain this heightened state of allergen-specific sensitisation, we measured typical DC-activating cytokines, released by bronchial epithelial cells early in the sensitisation process. TSLP and GM-CSF were below 

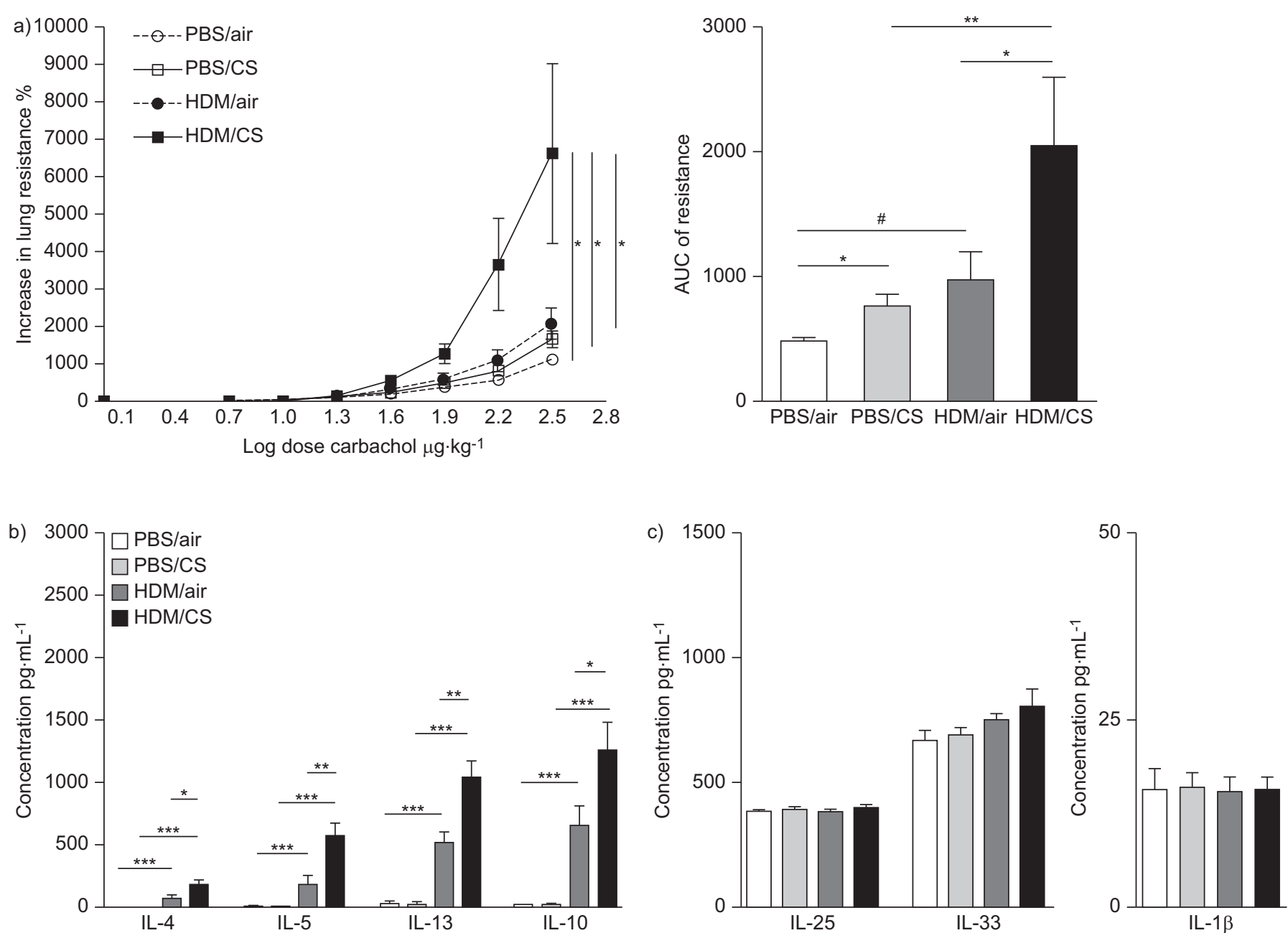

FIGURE 6. Airway hyperresponsiveness to carbachol and cytokine responses of mice simultaneously exposed to PBS or house dust mite (HDM) and 4 days of air or cigarette smoke (CS). a) Dose-response curve to carbachol and area under the curve (AUC); b) protein levels of interleukin (IL)-4, IL-5, IL-13 and IL-10 in the supernatant of HDM-restimulated lymph node cells; and c) measurements of IL-25, IL-33 and IL-1 $\beta$ in the supernatant of crushed lungs. Data are presented as mean \pm SEM; $n=10$ animals per group. *: $p<0.05 ;{ }^{* *}: p<0.01 ; * * *: p<0.001 ;{ }^{*}: p=0.051$.

detection limit, but IL-25, IL-33 and IL-1 $\beta$ were elevated in cigarette smoke-exposed mice (fig. 8e). IL-1 $\beta$ increased further after concomitant exposure to HDM and cigarette smoke.

\section{DISCUSSION}

In this paper, we have demonstrated that cigarette smoke exposure can play a determining role during allergic sensitisation and asthma development. We showed that concomitant exposure to cigarette smoke and a low dose of HDM results in a pronounced Th2-related asthmatic phenotype, which is hardly present when HDM alone is used. In addition, we demonstrated that, in the presence of allergens, acute cigarette smoke exposure is sufficient to cause sensitisation and subsequent asthma development, possibly by the amplified allergen transport of airway DCs towards the mLNs.

The strongest predictive factor for asthma development is the sensitisation to common environmental allergens, such as HDMs, grass pollen or animal dander. Epidemiological studies provide indirect clinical evidence that smoking is associated with increased sensitisation to HDM allergens. Smoke exposure is even correlated with higher asthma incidence and severity of the disease. Children in particular become more susceptible due to smoke exposure, as illustrated by the increased wheeze and asthma prevalence among children and young adolescents upon passive smoke inhalation [23].

Within our lab, we created a murine model, supporting the findings from epidemiological studies and using HDM as a clinically relevant allergen. HDM is the most significant source of indoor allergens, responsible for atopic symptoms in $10 \%$ of individuals. It is a complex mixture of various protein allergens and nonprotein compounds, with some allergens having the natural capacity to induce mucosal sensitisation through the respiratory tract [24]. Although the content of commercially available preparation of HDM extract can vary extensively [25], these extracts might be a good representation of the indoor HDM allergens present in our homes. To examine whether cigarette smoke can lower the threshold for asthma development, we first created a mild murine asthma model by down-titration of the HDM protein content until almost no asthmatic phenotype could be elicited (data not shown). Such 

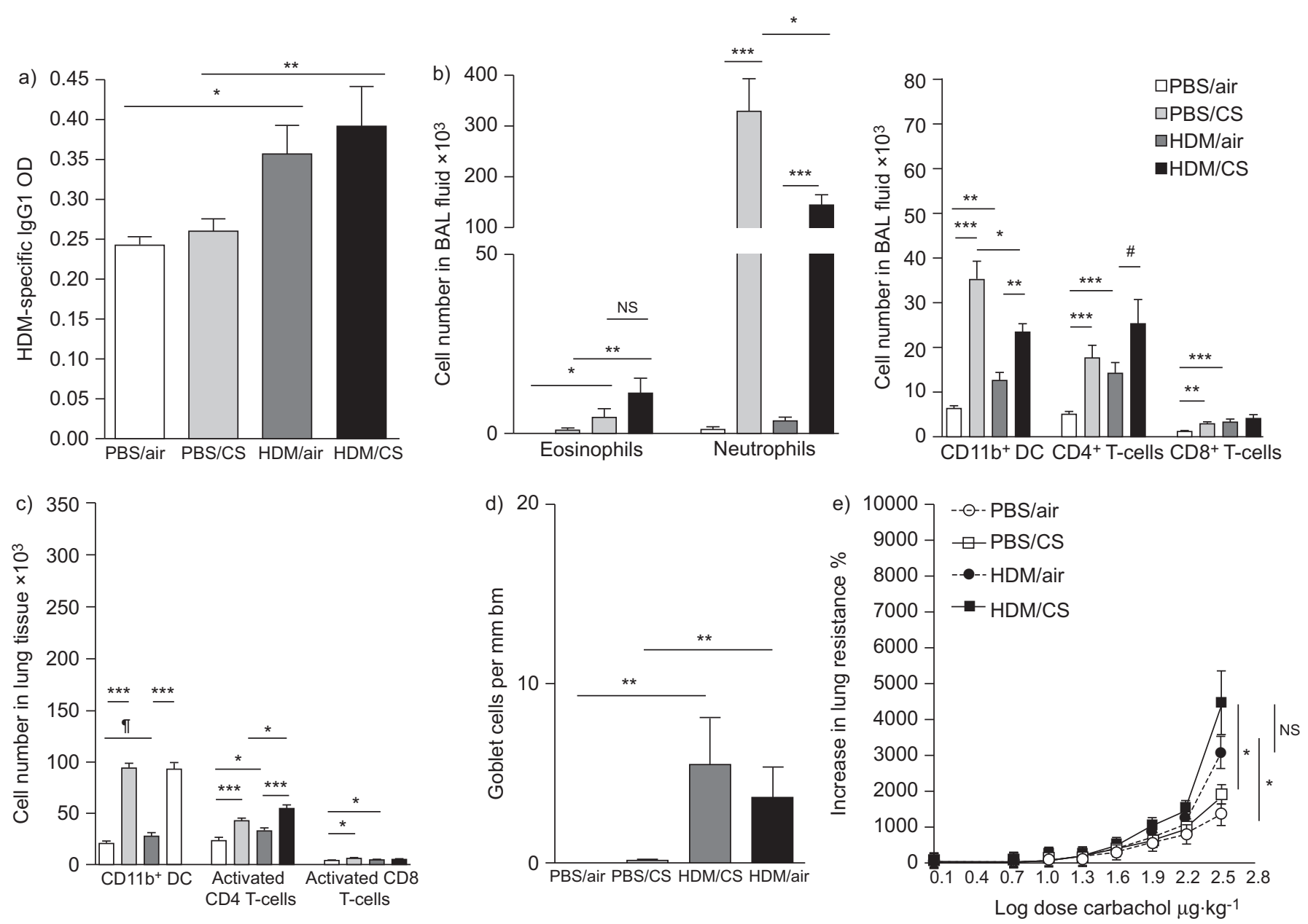

FIGURE 7. Immunoglobulins (Ig), inflammatory response, histopathological evaluation and airway hyperresponsiveness of mice simultaneously exposed to PBS or house dust mite (HDM) and air or cigarette smoke (CS) during the allergen challenge phase. a) HDM-specific lgG1; b) cell differentiation of bronchoalveolar lavage (BAL) fluid c) lung digest; d) quantification of goblet cells; and e) airway hyperresponsiveness to carbachol. Data are presented as mean \pm SEM; $n=10$ animals per group. OD: optical density; DC: dendritic cell; bm: Ns: nonsignificant. *: $p<0.05$; ${ }^{*}: p<0.01 ; * *: p<0.001 ;{ }^{*}: p=0.076 ;{ }^{\circ}: p=0.07$.

models are relevant to evaluate potential synergistic effects upon cigarette smoke inhalation.

In this paper, we demonstrate that cigarette smoke exposure facilitates and aggravates asthmatic disease, as illustrated by the increased eosinophils and neutrophils in BAL. These findings are in agreement with our previous work, investigating the role of cigarette smoke in asthma development with OVA as a "surrogate" allergen [14, 26]. However, OVA is not a naturally occurring allergen and prolonged exposure elicits inhalation tolerance, rather than allergic inflammation, in mice [27].

An important novelty of our study, using adolescent mice aged 6-8 weeks, is the striking result that only 3 days of cigarette smoke exposure during the initial allergen contact are sufficient to prime HDM-specific Th2 cells in the LNs. This process might be driven by the enhanced HDM transport of the airway DCs. Our findings suggest that adolescent smokers and young children may become more susceptible to allergic sensitisation and ensuing asthma development, due to (short) cigarette smoke inhalation. In our opinion, these results can be extrapolated to humans, since our murine cigarette smoke exposure protocol reaches carboxyhaemoglobin $(\mathrm{COHb})$ levels comparable to those in human smokers $[28,29]$ and since $\mathrm{COHb}$ levels in young children (aged 1-2 years) exposed to parental smoke are similar to those measured in adult smokers [30].

Furthermore, we focused on the release of innate pro-allergic cytokines, known to instruct DCs to mount Th2-mediated cell responses in the lung [31]. 3 weeks of HDM and cigarette smoke exposure resulted in significantly more IL-25, IL-33 and IL-1 $\beta$. In contrast, when stopping cigarette smoke exposure after the initial sensitisation, no differences in these cytokines were found 2 weeks after smoke cessation. This suggests a synergistic role for cigarette smoke, particularly during the ongoing allergic response, and illustrates the direct impact of cigarette smoke on airway epithelial cells and on the release of innate pro-Th2 cytokines, the driving force in activating DCs and ensuing asthma development. IL-1 $\beta$ and IL-33 were even increased after a single HDM administration concomitant with 3 days of smoke exposure, suggesting a role for these cytokines during the sensitisation phase and in facilitating the sensitisation process due to cigarette smoke. This idea is supported by WILLART et al. [32] who recently confirmed a role for these cytokines early in asthma development. By blocking IL-1 $\beta$ and 

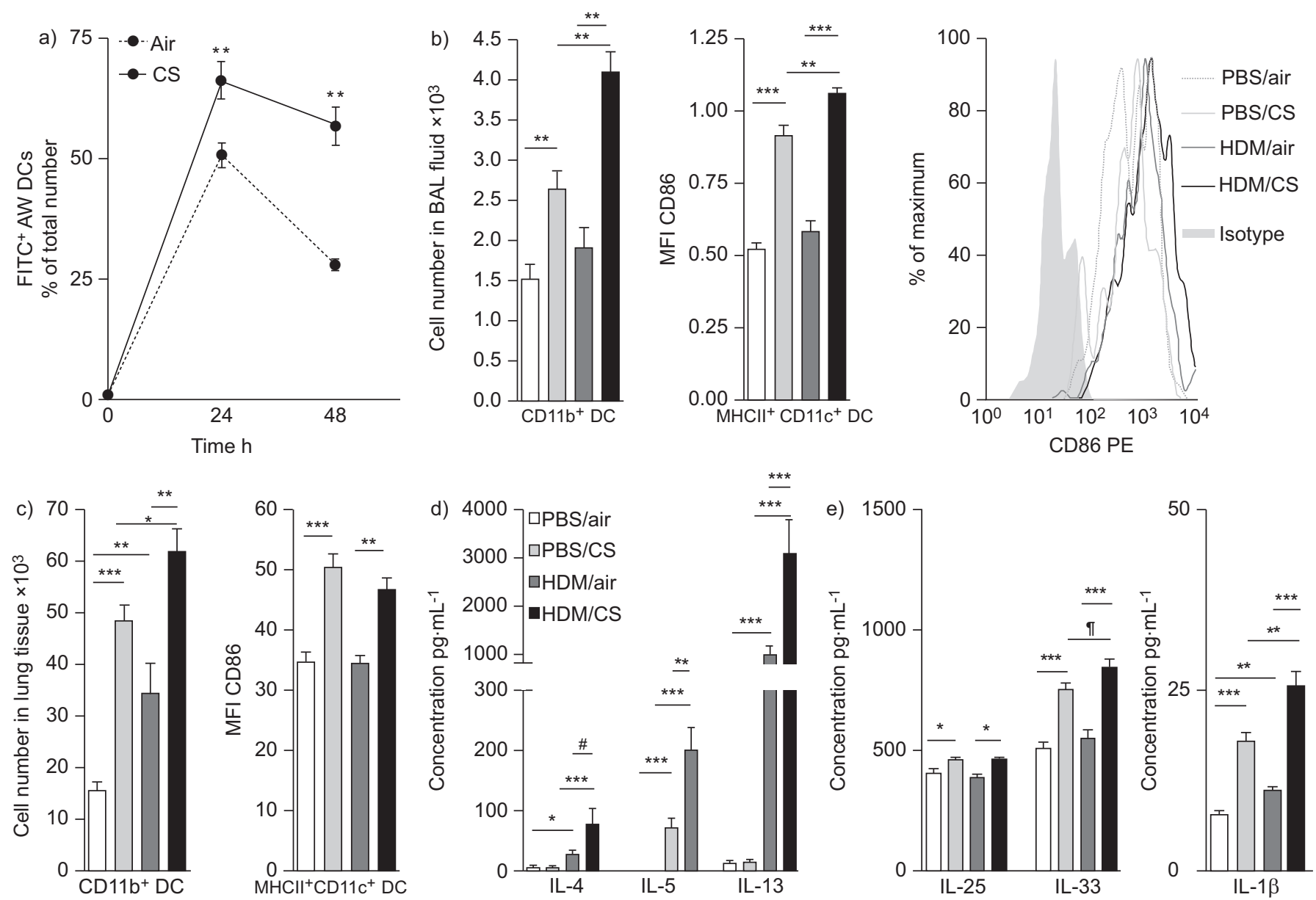

FIGURE 8. Migration, recruitment and maturation of pulmonary dendritic cells (DCs) and corresponding cytokine profiles upon PBS or house dust mite (HDM) and acute air or cigarette smoke (CS) exposure. a) DC migration to the mediastinal lymph nodes; b) cluster of differentiation (CD)11b DCs and expression of CD86 on bronchoalveolar lavage (BAL) DCs; c) lung DCs (calculated within the population of low autofluorescent, CD11 ${ }^{+}$and major histocompatibility complex (MHC) $I^{+}$DCs); d) protein levels of interleukin (IL)-4, IL-5 and IL-13 in HDM-restimulated lymph node cells; and e) measurements of IL-25, IL-33 and IL-1 $\beta$ in supernatant of crushed lungs. Data are presented as mean \pm SEM; $n=10$ animals per group. FITC: fluorescein isothiocyanate; AW: airway derived; MFI: mean fluorescence intensity; PE: phycoerythrin. *: $p<0.05$; ${ }^{* *}: p<0.01 ;{ }^{* * *}: p<0.001 ;{ }^{*}: p=0.07 ;{ }^{*}: p=0.059$

IL-33 signalling during HDM sensitisation, they demonstrated that IL-1 $\beta$ was involved in Th2 cytokine production, whereas IL-33 was crucial for BAL inflammation.

To our knowledge, this is the first in vivo model showing unambiguous synergy between cigarette smoke and HDM allergens. In line with our observation, RUSZNAK et al. [33] found increased inflammatory mediator release from primary in vitro cultures of human bronchial epithelial cells, after exposure to cigarette smoke and Der $\mathrm{p}$ allergens. BLACQUIÈRE et al. [34] examined the effect of maternal smoking during pregnancy. Upon HDM exposure, mouse offspring of smoking mothers showed increased airway wall remodelling and airway hyperresponsiveness, but no increase in inflammatory response or elevated Th2 cytokines could be demonstrated in $\mathrm{HDM} /$ cigarette smoke-exposed mice. MITCHELL and coworkers $[35,36]$ investigated the role of progesterone, in combination with or without cigarette smoke, in exacerbating allergic airway disease. Although different in experimental setup, they found some indications for increased allergic inflammation due to cigarette smoke; however, these were less pronounced than in our model. In contrast to our current findings, a recent study by BотеLHO et al. [37] using a murine model of established allergic asthma, reported significantly attenuated eosinophilia in BAL fluid of mice exposed to both HDM and cigarette smoke, together with decreased mucus production, and no difference in $\mathrm{CD}^{+}$T-cell activation nor airway hyperresponsiveness between HDM and, or cigarette smokeexposed mice.

Disparities between our data and the studies mentioned above might be related to fundamental differences in allergen and cigarette smoke exposure protocol, such as the use of alum as a Th2 skewing adjuvant $[35,36]$ or the timing, duration and intensity of smoke exposure. In addition, the variability between commercially available preparations of HDM extract (e.g. endotoxin content) may affect the development of potential Th2 responses in the lung [37].

Compared with the previous studies, our model is innovative, since we show synergy using a mild asthma model and a short cigarette smoke-exposure protocol. The clear distinction 
between the sensitisation and allergen challenge phase made it possible to examine the impact of cigarette smoke on different phases of asthma pathogenesis. Because of the diversity of asthma phenotypes, preclinical mouse models of combined exposures to allergens and environmental pollutants will become more important in the future. Combination models mimic more closely the real-life situation in humans and are therefore more reliable to provide mechanistic insights and to test potential therapeutic strategies.

In conclusion and in agreement with epidemiological studies, we provide biological mechanistic data, supporting the hypothesis that environmental factors, such as cigarette smoke, are risk factors for sensitisation and ensuing asthma development. We found that even short-term cigarette smoke exposure can lower the threshold for allergen sensitisation, making individuals more vulnerable to future asthma development.

\section{SUPPORT STATEMENT}

The present study was supported by the Concerted Research Action of the University of Ghent (BOF/GOA 01251504) and the Interuniversity Attraction Poles (IUAP) Program, Belgian State, Belgian Science Policy, Project P6/35. K.G. Tournoy is a senior clinical investigator with a grant from FWO-Vlaanderen.

\section{STATEMENT OF INTEREST}

None declared.

\section{ACKNOWLEDGEMENTS}

We would like to thank Greet Barbier, Eliane Castrique, Indra De Borle, Philippe De Gryze, Katleen De Saedeleer, Anouck Goethals, MarieRose Mouton, Ann Neessen, Christelle Snauwaert and Evelyn Spruyt (all Laboratory for Translational Reasearch in Obstructive Pulmonary Diseases, Ghent University, Ghent, Belgium) for their excellent technical assistance.

\section{REFERENCES}

1 Tovey ER, Marks GB. It's time to rethink mite allergen avoidance. J Allergy Clin Immunol 2011; 128: 723-727.

2 D'Amato G, Liccardi G, D'Amato M, et al. Environmental risk factors and allergic bronchial asthma. Clin Exp Allergy 2005; 35: $1113-1124$

3 Pietinalho A, Pelkonen A, Rytila P. Linkage between smoking and asthma. Allergy 2009; 64: 1722-1727.

4 Polosa R, Russo C, Caponnetto P, et al. Greater severity of new onset asthma in allergic subjects who smoke: a 10-year longitudinal study. Respir Res 2011; 12: 16.

5 Comhair SA, Gaston BM, Ricci KS, et al. Detrimental effects of environmental tobacco smoke in relation to asthma severity. PLoS One 2011; 6: e18574.

6 Boulet LP, Lemiere C, Archambault F, et al. Smoking and asthma: clinical and radiologic features, lung function, and airway inflammation. Chest 2006; 129: 661-668.

7 Thomson NC, Spears M. The influence of smoking on the treatment response in patients with asthma. Curr Opin Allergy Clin Immunol 2005; 5: 57-63.

8 Chaudhuri R, McSharry C, McCoard A, et al. Role of symptoms and lung function in determining asthma control in smokers with asthma. Allergy 2008; 63: 132-135.

9 Jarvis D, Chinn S, Luczynska C, et al. The association of smoking with sensitization to common environmental allergens: results from the European Community Respiratory Health Survey. J Allergy Clin Immunol 1999; 104: 934-940.
10 Oberg M, Jaakkola MS, Woodward A, et al. Worldwide burden of disease from exposure to second-hand smoke: a retrospective analysis of data from 192 countries. Lancet 2011; 377: 139-146.

11 Piipari R, Jaakkola JJ, Jaakkola N, et al. Smoking and asthma in adults. Eur Respir J 2004; 24: 734-739.

12 Polosa R, Knoke JD, Russo C, et al. Cigarette smoking is associated with a greater risk of incident asthma in allergic rhinitis. J Allergy Clin Immunol 2008; 121: 1428-1434.

13 Rumold R, Jyrala M, Diaz-Sanchez D. Secondhand smoke induces allergic sensitization in mice. J Immunol 2001; 167: 4765-4770.

14 Robays LJ, Lanckacker EA, Moerloose KB, et al. Concomitant inhalation of cigarette smoke and aerosolized protein activates airway dendritic cells and induces allergic airway inflammation in a TLR-independent way. J Immunol 2009; 183: 2758-2766.

15 Moerloose KB, Pauwels RA, Joos GF. Short-term cigarette smoke exposure enhances allergic airway inflammation in mice. Am J Respir Crit Care Med 2005; 172: 168-172.

16 Melgert BN, Postma DS, Geerlings M, et al. Short-term smoke exposure attenuates ovalbumin-induced airway inflammation in allergic mice. Am J Respir Cell Mol Biol 2004; 30: 880-885.

17 Van Hove CL, Moerloose K, Maes T, et al. Cigarette smoke enhances Th-2 driven airway inflammation and delays inhalational tolerance. Respir Res 2008; 9: 42.

18 Thatcher TH, Benson RP, Phipps RP, et al. High-dose but not lowdose mainstream cigarette smoke suppresses allergic airway inflammation by inhibiting T cell function. Am J Physiol Lung Cell Mol Physiol 2008; 295: L412-L421.

19 Bracke KR, D'hulst AI, Maes T, et al. cigarette smoke-induced pulmonary inflammation and emphysema are attenuated in CCR6-deficient mice. J Immunol 2006; 177: 4350-4359.

20 Vermaelen KY, Carro-Muino I, Lambrecht BN, et al. Specific migratory dendritic cells rapidly transport antigen from the airways to the thoracic lymph nodes. J Exp Med 2001; 193: 51-60.

21 Van Hove CL, Maes T, Cataldo DD, et al. Comparison of acute inflammatory and chronic structural asthma-like responses between C57BL/6 and BALB/c mice. Int Arch Allergy Immunol 2009; 149: 195-207.

22 Hammad H, Chieppa M, Perros F, et al. House dust mite allergen induces asthma via Toll-like receptor 4 triggering of airway structural cells. Nat Med 2009; 15: 410-416.

23 Burke H, Leonardi-Bee J, Hashim A, et al. Prenatal and passive smoke exposure and incidence of asthma and wheeze: systematic review and meta-analysis. Pediatrics 2012; 129: 735-744.

24 Ishii A, Takaoka M, Matsui Y. Production of guinea pig reaginic antibody against the house dust mite extract, Dermatophagoides pteronyssinus, without adjuvant. Jpn J Exp Med 1977; 47: 377-383.

25 Geissler W, Maasch HJ, Winter G, et al. Kinetics of allergen release from house dust mite Dermatophagoides pteronyssinus. J Allergy Clin Immunol 1986; 77: 24-31.

26 Moerloose KB, Robays LJ, Maes T, et al. Cigarette smoke exposure facilitates allergic sensitization in mice. Respir Res 2006; 7: 49.

27 Van Hove CL, Maes T, Joos GF, et al. Prolonged inhaled allergen exposure can induce persistent tolerance. Am J Respir Cell Mol Biol 2007; 36: 573-584.

28 Bracke KR, D'hulst AI, Maes T, et al. Cigarette smoke-induced pulmonary inflammation, but not airway remodelling, is attenuated in chemokine receptor 5-deficient mice. Clin Exp Allergy 2007; 37: 1467-1479.

29 Macdonald G, Kondor N, Yousefi V, et al. Reduction of carboxyhaemoglobin levels in the venous blood of cigarette smokers following the administration of carbogen. Radiother Oncol 2004; 73: 367-371.

30 Yee BE, Ahmed MI, Brugge D, et al. Second-hand smoking and carboxyhemoglobin levels in children: a prospective observational study. Paediatr Anaesth 2010; 20: 82-89.

31 Hammad H, Lambrecht BN. Dendritic cells and airway epithelial cells at the interface between innate and adaptive immune responses. Allergy 2011; 66: 579-587. 
32 Willart MA, Deswarte K, Pouliot $\mathrm{P}$, et al. Interleukin- $1 \alpha$ controls allergic sensitization to inhaled house dust mite via the epithelial release of GM-CSF and IL-33. J Exp Med 2012; 209: 1505-1517.

33 Rusznak C, Sapsford RJ, Devalia JL, et al. Interaction of cigarette smoke and house dust mite allergens on inflammatory mediator release from primary cultures of human bronchial epithelial cells. Clin Exp Allergy 2001; 31: 226-238.

34 Blacquière MJ, Timens $\mathrm{W}$, Melgert $\mathrm{BN}$, et al. Maternal smoking during pregnancy induces airway remodelling in mice offspring. Eur Respir J 2009; 33: 1133-1140.
35 Mitchell VL, Van Winkle LS, Gershwin LJ. Environmental tobacco smoke and progesterone alter lung inflammation and mucous metaplasia in a mouse model of allergic airway disease. Clin Rev Allergy Immunol 2012; 43: 57-68.

36 Mitchell VL, Gershwin LJ. Progesterone and environmental tobacco smoke act synergistically to exacerbate the development of allergic asthma in a mouse model. Clin Exp Allergy 2007; 37: 276-286.

37 Botelho FM, Llop-Guevara A, Trimble NJ, et al. Cigarette smoke differentially affects eosinophilia and remodeling in a model of house dust mite asthma. Am J Respir Cell Mol Biol 2011; 45: 753-760. 